\title{
Using the Empowerment Scale with Unemployed People in Lifelong Learning: Is the Tool Sound and Useful?*
}

\author{
Raymond Meyers, Anne Pignault, Claude Houssemand \\ University of Luxembourg, Institute of LifeLong Learning and Guidance (LLLG), Esch-sur-Alzette, Luxembourg
}

\begin{abstract}
Empowerment is a widely used construct in research on social work, mental health and community interventions, but has only been exploited indirectly with the unemployed. But job finding is an important dimension of empowerment and could be used to test the accuracy of the concept and of its measures. The Making Decisions Empowerment Scale was used with 97 unemployed people who had been jobless for 6 months. Even though the psychometric qualities of the 5 subscales and the total scale were mixed, convergent and discriminant validity with several adaptive and non-adaptive dimensions could be established for the global scale and for the Esteem, Power, Control and, to a lesser degree, the Activism subscales. The results were only marginally better for the 28 items global scale compared to the 9 items Esteem scale. Empowerment could be adequately modelled by using three dimensions: change coping, depression, and chance control of unemployment. Comparing 6 months later those who had found a job with the still unemployed, the 2 groups differed significantly on 2 of the 5 subscales (Activism and Control) though not on the total empowerment scale, nor on the other psychometric scales. The results throw some doubt on the accuracy of an aggregate measure that sums up divergent dimensions. Instead, it is proposed that more specific and individualised constructs be used, at least in unemployment research.
\end{abstract}

Keywords: unemployment, empowerment, job search, scale, Luxembourg

\section{Introduction}

One of the major issues in contemporary Western societies is how to get people with mental and social problems to take control of their lives and to contribute in a significant way to improvements with regards to their difficulties (Perkins, 1995). As a concept, empowerment has become a widely used construct in research on social work, mental health and community interventions (Zimmerman, 1995). The multi-dimensional and heterogenic character of the construct is generally highlighted. For example, Chamberlin (1997) cites access to information, ability to make decisions, assertiveness and self-esteem as key elements of empowerment, together with a list of additional basic elements. Gibson (1991), trying to clarify the concept in the health-care domain, showed that a great number of characteristics are associated to the concept, making it uneasy to implement empowerment in a consistent way. A recent review of use of the term "empowerment" in relation to care and education of patients with chronic disease (Aujoulat, d'Hoore, \& Deccache, 2007) concluded that there was no

\footnotetext{
*Acknowledgements: This research was supported by the Luxembourg National Research Fund in the framework of the VIVRE Program; grant number FNR/02/05/07.

Raymond Meyers, Ph.D., senior lecturer, University of Luxembourg, Institute of LifeLong Learning and Guidance (LLLG). Anne Pignault, Ph.D., associate professor, University of Luxembourg, Institute of LifeLong Learning and Guidance (LLLG). Claude Houssemand, Ph.D., professor, University of Luxembourg, Institute of LifeLong Learning and Guidance (LLLG).
} 
consistent definition of patient empowerment, authors often referring to some anticipated outcome, such as self-management or self-efficacy to explain what they mean.

The objective of this paper is two-fold. First, the construct has only been exploited marginally or indirectly with the unemployed. Studies typically consider unemployment as one dimension of lack of power (e.g., Hansson \& Björkman, 2005), or job finding as part of recovering from psychiatric disabilities (Provencher, Gregg, Mead, \& Mueser, 2002). For example, Wowra and McCarter (1999) found in a sample outpatient mental health population that respondents with full-time jobs scored significantly higher on empowerment measured with the Making Decisions Empowerment Scale (Rogers, Chamberlin, Ellison, \& Crean, 1997) than those without full-time jobs. Kirsh (2000), using the same scale with small samples of employed and unemployed mental health consumers, found no significant difference between the two groups. These two studies are only cross-sectional and no conclusion on causality can be drawn.

Unemployment has been shown consistently to be linked to lack of mental health and wellbeing (McKee-Ryan, Song, Wanberg, \& Kinicki, 2005). Even if the mental health problems may be reversible through reemployment (Kessler, Turner, \& House, 1989; Taris, 2002), it has been shown that unemployment may have long-lasting effects on subjective well-being, these effects continuing after several years of reemployment (Lucas, Clark, Georgellis, \& Diener, 2004). The reverse question is also of interest and should be investigated further, especially in the context of active labour market policies: Can psychological dimensions like empowerment predict job search strategies and duration of unemployment? If empowerment means a better control of ones life and more social adjustment, people showing a higher level of empowerment should be less at risk of becoming long term unemployed and should find jobs more quickly, which could be tested easily.

The second objective is more conceptual. Critics have emphasized the risk of catch-phrasing and empty rhetoric, the discourse of empowerment being overruled in practice by organisational structures and professional attitudes (Townsend, 1998). Our concern is more in line with the work of Arneson and Ekberg (2006), which showed the extreme heterogeneity of the concept and of the measures of empowerment in working life. We want to assess if the multidimensional character of the construct allows convergent and divergent as well as concurrent and predictive validity of the whole aggregate, over and above more basic concepts being part of the construct. For example, does a score of empowerment have better predictive validity than self-esteem, self-efficacy, competence, proactivity, optimism, control, etc., which are current constructs of psychological research on unemployment, or as the different subscales of the global measure capturing precisely these more elemental constructs?

The two research questions have very practical implications, for example in lifelong learning and active labour market policy: Does an empowerment scale permit prediction of unemployment duration and could it be used in the early detection and counselling of people at risk becoming long-term unemployed?

\section{The Making Decisions Empowerment Scale}

The Making Decisions Empowerment Scale (Rogers, Chamberlin, Ellison, \& Crean, 1997) was developed as a measure "that can be used in a variety of settings" (Rogers et al., 1997, p. 1043), contrary to more domain-specific measures designed for example for work (e.g., Spreitzer, 1995; for a review of work-based instruments see Arneson \& Ekberg, 2006) or for people with disabilities (e.g., Bolton \& Brookings, 1998). The Making Decisions scale was designed with the assistance of consumers of mental health services and first 
tested on 271 members of six self-help programs in the USA. The scale has been used in cross-sectional designs with consumers of mental health services (Corrigan, 2006; Corrigan, Faber, Rashid, \& Leary, 1999; Hansson \& Björkman, 2005; Wowra \& McCarter, 1999), consumers with disabilities (Kosciulek \& Merz, 2001), and HIV-positive injection drug-using women and their serodiscordant male partners (Latka et al., 2006). It is nowadays probably the mostly used tool to assess empowerment in the field of social work, mental health and public health (Castelein, van der Gaag, Bruggeman, van Busschbach, \& Wiersma, 2008).

Factor analyses revealed five factors: self-esteem-self-efficacy, power-powerlessness, community activism and autonomy, optimism and control over the future, righteous anger (Rogers et al., 1997; Rogers, Ralph, \& Salzer, 2010). This factor structure was confirmed by Wowra and McCarter (1999) on a sample of an outpatient mental health population. Corrigan, Faber, Rashid, and Leary (1999) conducted a study with a somewhat different structure based on seven factors (self-efficacy, powerlessness, self-esteem, effecting change, optimism/control over the future, righteous anger, and group/community action). Analysis of the subscales yielded two superordinate factors consistent with self- and community orientations to empowerment. Scales which loaded significantly on the self-orientation factor included a sense of self-efficacy, positive self-esteem, and optimism about the future. Scales which loaded on community orientation included an interest in community action, a lack of feeling powerless in the face of the community, and a confidence in effecting change.

The Making Decisions Empowerment Scale is interesting for our purpose, because it has a global scale as well as 5 specific subscales, that could be used to test convergent and discriminant validity with similar, well-studied constructs (like self-esteem, self-efficacy, perceived control, employment commitment, perceived stress, etc.). The different scales could also be used in a longitudinal study to assess the predictive validity with later job search outcomes, compared to the same more classic measures. We decided to include several psychometric constructs in our assessment, in order to evaluate convergent discrimant and predictive validity. We hereafter present the several theoretical hypotheses.

Perceived control of unemployment is a generalised belief about what controls outcomes in unemployment, job search processes, and job search results. These are, in line with Levenson (1973), three types of control perceptions: internal, chance, and powerful others. People with a higher level of empowerment should score higher on internal and lower on chance and powerful others perceived control of unemployment. The Control subscale referring to control perceptions, would be expected to be positively related to internal and negatively linked to chance and powerful others control perceptions. The Power subscale should also be positively related to internal and negatively linked to chance and powerful others control.

Self-esteem is a part of the empowerment construct, one of the subscales of the chosen tool being named after it. So self-esteem should have a significant relation to global empowerment and to the Esteem subscale.

Self-efficacy, also part of the empowerment construct and particularly of the Esteem scale (which is called self-esteem-self-efficacy in the original article by Rogers et al., 1997), should be found to correlate significantly with the global scale and with the Esteem subscale. We would also expect self-efficacy to be related to the Power, Activism and Control subscales.

Coping has been theorized in the cybernetic coping theory of Edwards (1992), who distinguishes five types of coping: changing the stressful situation, accommodation, devaluation of the stressor, avoidance of the stressful situation, and symptom reduction (Edwards \& Baglioni, 1993). Coping is an important dimension of empowerment, people who have a higher level of empowerment should use more change and accommodation 
coping and less devaluation and avoidance coping. The adaptative role of symptom reduction coping is less obvious. We also expect the Activism subscale to be related to change coping.

Employment commitment is the importance a person gives to having a job. It is an important dimension in unemployment research, even if a recent meta-analysis by Kanfer, Wanberg, and Kantrowitz (2001) has shown that it is more strongly related to job search behaviour than to job finding itself. It is expected that people with a higher level of empowerment also give more importance in their lives to having a job.

Social support and satisfaction with social support are also important parts of empowerment, empowered people having more opportunity to rely on a network of people to give them support and they should also be more satisfied with this support.

In addition, we measured three dimensions of mental health to test the link between measured empowerment and psychological well-being and/or mental health. Psychological distress (or perceived ill-being), as mostly assessed by the General Health Questionnaire (GHQ) (Goldberg, 1972) has been used in a large number of studies to assess levels of well-being. People who are more empowered should have a lower level of ill-being. The same is true for perceived stress and depression levels: subjects with higher empowerment should have less perceived stress and be less depressed.

\section{Sample and Method}

The population of the study was recruited at the two major employment agencies of Luxembourg. It was constituted of 97 unemployed people (60 men; 37 women; ages ranging from 16 to 57 with a mean age of 35), who were without a job for 6 months and so were at risk of becoming long-term unemployed 6 months later. The official limit at which people are considered to be long-term unemployed is 12 months. In Luxembourg, the labour market is very favourable, with low unemployment rate, high job creation and relatively generous social protection. Typically, around 55\% of unemployed persons find a new job after 6 months, those who are still unemployed at that time, are more at risk of becoming long-term unemployed. It is also worth mentioning, that after 12 months, no further unemployment benefits are provided, however people may apply for a different social welfare system that is not limited in time.

A computer-based user-friendly assessment tool was applied to administer the questionnaires to the unemployed people. No computer skills were necessary to fill in the questionnaire because tablet-PCs were used; these laptops allow the keyboard to be hidden and a pencil to be used to choose the answers on the screen. Participants had the choice between three languages: French, German and Portuguese.

\section{Measures}

In addition to the Making Decisions Empowerment Scale, several other psychological dimensions were measured simultaneously. All, but two of the dimensions tested, were measured by using published questionnaires. The existing English, French or German versions of scales were translated into French, German and Portuguese by native speakers of these languages, in order to have three complete linguistic versions of the whole tool. This permitted the subjects to complete the questionnaires in the language most familiar to them. Back-translations were made in order to verify the accuracy of the translations. Two scales were developed for the study.

"Empowerment” was measured by the Making Decisions (MD) Empowerment Scale (Rogers et al., 1997), a 28 items instrument initially created to evaluate empowerment among users of mental health services. The 5 subscales of the initial validation study were also used: Self-esteem-self-efficacy (9 items); 
Power-powerlessness (8 items); Community activism and autonomy (6 items); Optimism and control over the future (4 items) and Righteous anger (4 items). For simplicity reasons, we use the shorter terms introduced by Wowra and McCarter (1999): Esteem (E), Power (P), Activism (Ac), Control (C) and Anger (An). Three items were each represented in 2 scales. Items are rated on a 4-point scale ranging from "Absolutely disagree" (1) to "Absolutely agree” (4). Higher scores on the different scales indicate a better level of empowerment.

"Perceived control of unemployment" was measured by an 18 items scale constructed for the study, the Perceived Control of Unemployment Scale (PCUS). Based on the theory of Levenson (1973), this scale distinguishes three dimensions of control of the unemployment and job search situations: internal, chance and powerful others. We used the Multidimensional Health Locus of Control (MHLC) Scales (Wallston, Wallston, \& DeVellis, 1978) but changed the context of the items. Example items for the three dimensions are: "It is my own behaviour which determines how soon I find a job", "Luck plays a big part in determining how soon I will find a job" and "Having regular contact with the administration is the best way for me to find a job". Items were rated on a 4-point scale ranging from "Absolutely disagree” (0) to "Absolutely agree” (3).

"Self-esteem” was assessed by the Rosenberg Self-Esteem Scale (RSES; Rosenberg, 1965), a 10 items instrument largely used for assessing general self-esteem. Items were rated on a 4-point scale ranging from "Strongly disagree" (0) to "Strongly agree” (3).

"Self-efficacy" was measured by the French adaptation of the General Self-Efficacy Scale (GSES). This scale has 21 items instead of 23 in the original instrument (Sherer et al., 1982). Items were rated on a 5-point scale ranging from "Absolutely disagree" (0) to "Absolutely agree" (4).

"Coping” was measured by the 15 items Cybernetic Coping Scale (CCS; Guppi et al., 2004), a shortened version of the 20 items and 40 items versions (Edwards \& Baglioni, 1993). With this instrument, coping is considered to be of five different types: Change the Situation, Accommodation, Devaluation, Avoidance, and Symptom Reduction. Items were rated on a 5-point scale ranging from "Do not use at all" (1) to "Use very much" (5).

"Employment commitment" was measured by a 16 items scale constructed for the study, the Employment Commitment Scale (ECS). Example items are: "I feel I have a goal in life when I work" and "For me, work is not so important". Items were rated on a 5-point scale ranging from "Absolutely disagree" (0) to "Absolutely agree” (4).

"Social support” was measured by the 6 items Social Support Questionnaire (SSQ6; Sarason, Levine, Basham, \& Sarason, 1983). The scale assesses social support as well as satisfaction with this support. For the computer-version we had to change the formulation of the items: Subjects were not asked to give the names of the support persons, only the number of people. On the social support scale, subjects can indicate from 0 to 9 support persons. Items on the satisfaction scale were rated on a 6-point scale ranging from "Very unsatisfied" (1) to "Very satisfied" (6).

"Psychological distress" was measured through the 12 items General Health Questionnaire (GHQ12; Goldberg, 1972), a widely used scale evaluating lack of well-being. Items were rated on a 4-point scale ranging from (0) to (3), with changing answers depending on questions. We preferred this Likert-scaling to the traditional bi-modal scaling (0-0-1-1) advocated by Goldberg (1972), because it allows a better consideration of fine differences in subjects' answers.

"Perceived stress" was measured by the 14 items Perceived Stress Scale (PSS; Cohen, Kamarck, \& Mermelstein, 1983). Items were rated on a 5-point scale ranging from "Never” (0) to "Very often” (4). 
“Depression” was measured by the 20 items Center for Epidemiologic Studies-Depression Scale (CES-D; Radloff, 1977), a widely used instrument. Items were rated on a 4-point scale ranging from "Rarely or none of the time" (0) to "Most or all of the time" (3).

The dependant measure was employment status 6 months later, meaning 12 months after the registration as unemployed. This information was extracted anonymously from the unemployment records of the participants.

\section{Results}

No differences between genders were found, and for future analyses the two groups were merged. Means and standard deviations of the different psychometric measures at the beginning of the study are shown in Table 1. Intercorrelations between psychometric scales at the same time are shown in Table 2.

Table 1

Descriptive Statistics for Psychometric Variables at 6 Months of Unemployment $(N=97)$

\begin{tabular}{|c|c|c|c|c|c|}
\hline Construct & Scale & Number of items & Cronbach’s alpha & Mean & $\begin{array}{l}\text { Standard } \\
\text { deviation }\end{array}$ \\
\hline Empowerment & MD & 28 & 0.80 & 82.2 & 8.44 \\
\hline Empowerment-Esteem & MD-E & 9 & 0.91 & 29.6 & 4.80 \\
\hline Empowerment-Power & MD-P & 8 & 0.66 & 19.7 & 3.59 \\
\hline Empowerment-Activism & MD-Ac & 6 & 0.81 & 19.2 & 3.01 \\
\hline Empowerment-Control & MD-C & 4 & 0.60 & 9.7 & 1.70 \\
\hline Empowerment-Anger & MD-An & 4 & 0.17 & 9.7 & 1.70 \\
\hline Control-Internal & PCUS-I & 6 & 0.65 & 10.1 & 2.98 \\
\hline Control-Chance & PCUS-C & 6 & 0.67 & 7.4 & 2.97 \\
\hline Control-Powerful others & PCUS-P & 6 & 0.44 & 7.5 & 2.50 \\
\hline Self-esteem & RSES & 10 & 0.82 & 21.1 & 4.69 \\
\hline Self-efficacy & SES & 21 & 0.80 & 59.9 & 10.26 \\
\hline Change situation coping & CCS & 3 & 0.78 & 10.3 & 2.23 \\
\hline Accommodation coping & CCS & 3 & 0.71 & 10.1 & 2.04 \\
\hline Symptom reduction coping & CCS & 3 & 0.60 & 8.9 & 2.16 \\
\hline Devaluation coping & CCS & 3 & 0.76 & 8.0 & 2.65 \\
\hline Avoidance coping & CCS & 3 & 0.83 & 7.3 & 2.69 \\
\hline Employment commitment & ECS & 16 & 0.84 & 62.7 & 9.70 \\
\hline Social support & SSQ6 & 6 & 0.93 & 21.7 & 12.85 \\
\hline Satisfaction social support & SSQ6 & 6 & 0.96 & 26.1 & 7.38 \\
\hline Psychological distress & GHQ12 & 12 & 0.92 & 13.5 & 7.53 \\
\hline Perceived stress & PSS & 14 & 0.84 & 24.2 & 8.18 \\
\hline Depression & CES-D & 20 & 0.93 & 17.0 & 11.18 \\
\hline
\end{tabular}

\section{Reliability, Convergent and Divergent Validity}

The different empowerment scales show a good internal consistency, as measured with Cronbach's alpha, with the exception of the Anger scale, which is close to zero. Results with the Anger scale in this study should be considered with extreme caution. The other psychometric scales have satisfactory or good internal consistencies, with the exception of powerful others perceived control, which is very low.

Convergent and discrimant analysis could be further processed through the multiple bivariate correlations of Table 2. Data show that the overall scale correlates positively with the sub-scales and that most, but not all subscales are interrelated. In particular, the Power scale only correlated with the Activism and Control 
subscales but not with the psychometrically unsound Anger scale. Esteem did not correlate with the Power and the Anger subscales.

Table 2

Intercorrelations Between Psychometric Variables at 6 Months of Unemployment $(N=97)$

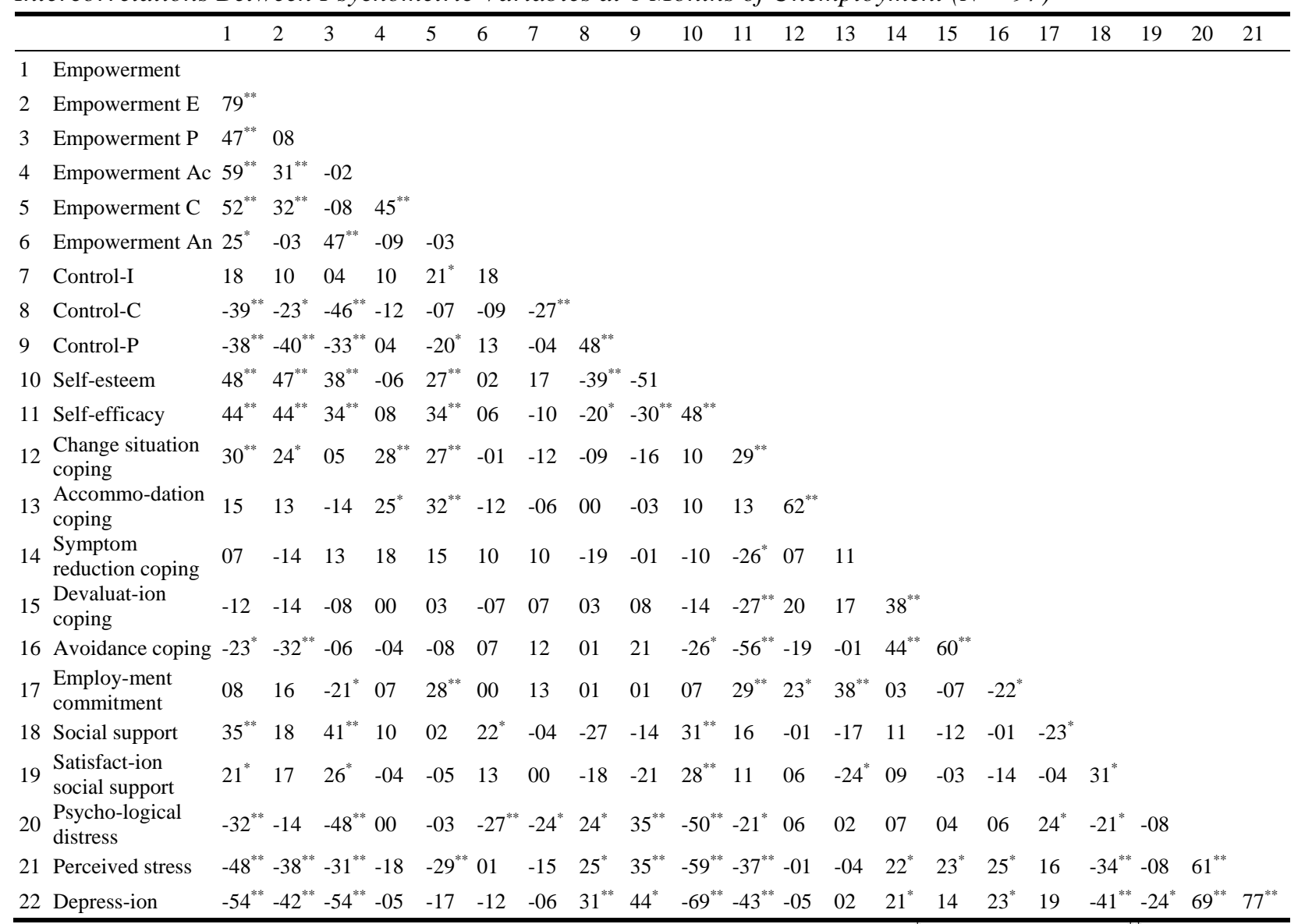

Notes. Decimals omitted; E = Esteem; P = Power; A = Activism; C = Control; An = Anger; ${ }^{*} p<0.05$, two-tailed; ${ }^{* *} p<0.01$, two-tailed.

The global empowerment scale is significantly positively correlated with self-esteem, self-efficacy, change coping, social support, and satisfaction with social support. The same scale is negatively correlated with chance perceived control of unemployment, powerful others perceived control of unemployment, avoidance coping, psychological distress, perceived stress and depression.

The Esteem scale correlated positively with self-esteem, self-efficacy, change coping and negatively with chance perceived control of unemployment, powerful others perceived control of unemployment, avoidance coping, perceived stress and depression. The Power scale correlated positively with self-esteem, self-efficacy, social support, satisfaction with social support and negatively with chance perceived control of unemployment, powerful others perceived control of unemployment, employment commitment, psychological distress, perceived stress and depression.

The Activism scale was only positively correlated with change coping. The Control scale was positively correlated with internal control, self-esteem, self-efficacy, change coping, employment commitment and 
negatively correlated with powerful others perceived control of unemployment and perceived stress. The Anger scale correlated only negatively with psychological distress, but the alpha reliability of the scale is so low that this result has no real meaning.

Most of our a priori theoretical links could be confirmed by bivariate correlation calculations between variables. There were several additional, unexpected positive or negative correlations that were significant; these relations could mostly fit with the theory. As can be seen from Table 2 (columns 1 and 2), correlations for the single Esteem subscale (9 items) were nearly as significant as for the global empowerment scale (28 items).

In addition, multiple regressions were performed in order to asses how much of the global empowerment scale could be explained by the well-known constructs measured simultaneously and that could provide insight into the nomological network associated with empowerment. We tested a statistical model where global empowerment was the dependant variable and all the other scales were independent predictors. One model gave significant results (Table 3). By entering depression, change coping and chance control of unemployment, significant increases in $R$ are obtained, the three dimensions accounting for a multiple $R$ of 0.648 or $42 \%$ of the variance. Adding sex or age did not change the outcome.

Table 3

Summary of Regression Analyses With Empowerment as Dependant Variable

\begin{tabular}{lllll}
\hline Model & Predictors & $R$ & $R^{2}$ & $R^{2}$ change \\
\hline 1a & Dep & 0.544 & 0.296 & \\
1b & Dep, CCop & 0.611 & 0.373 & +0.077 \\
1c & Dep, CCop, CCont & 0.648 & 0.419 & +0.046 \\
\hline
\end{tabular}

Note . Dep = Depression; CCop = Change Coping; CCont = Chance Perceived Control of Unemployment.

We performed structural equation modelling using Amos 6.0 to verify the first model. Results are shown in Figure 1. It shows that global empowerment can be adequately modelled by using three dimensions, change coping, depression, and chance perceived controlled of unemployment. Empowerment correlates 0.26 with change coping, -0.47 with depression, and -0.23 with chance perceived controlled of unemployment. There is a moderate correlation between depression and chance perceived control $(p=0.31)$. The fit of the whole model with data is good $(\mathrm{GFI}=0.995$; $\mathrm{AGFI}=0.977)$.

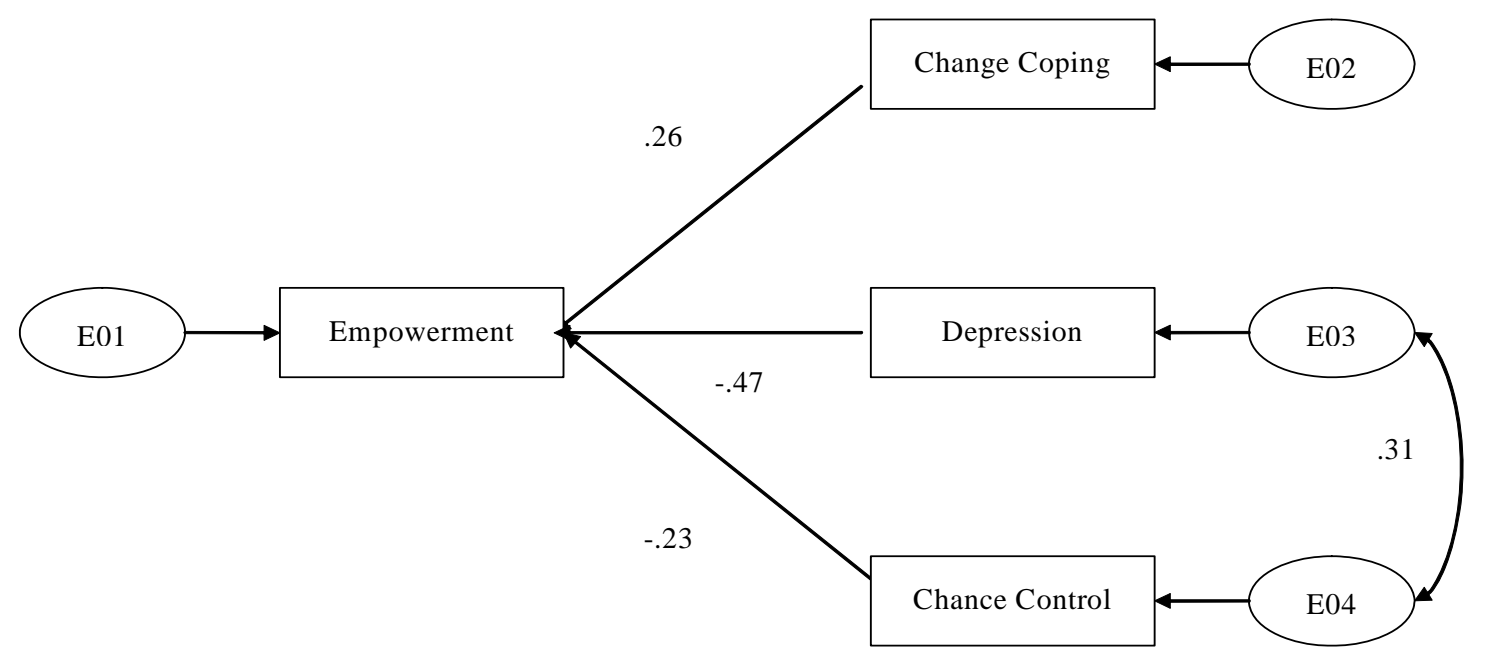

Figure 1. Structural Equation Modelling of Global Empowerment, GFI = 0.995; AGFI = 0.977. 


\section{Predictive Validity of Empowerment on Unemployment Duration}

Means and standard deviations on the different empowerment scales for the two employment statuses (employed vs. unemployed) are shown in Table 4, together with ANOVA tests of these differences. Results show that the two groups differed significantly only on two of the 5 subscales (Activism and Control) and not on the total empowerment scale. From the other psychometric constructs, only internal perceived control nearly reached significance $(p=0.074)$, all the others did not.

Table 4

Between Group Differences at 12 Months After Unemployment Registration for Psychometric Variables Measured at 6 Months of Unemployment $(N=97)$

\begin{tabular}{|c|c|c|c|c|c|c|}
\hline \multirow{2}{*}{ Variable } & \multicolumn{2}{|c|}{ Employed $(N=32)$} & \multicolumn{2}{|c|}{ Unemployed $(N=65)$} & \multicolumn{2}{|c|}{ ANOVA } \\
\hline & $M$ & $S D$ & $M$ & $S D$ & $F$ & Sig. \\
\hline Empowerment & 84.0 & 7.66 & 81.3 & 8.71 & 2.263 & 0.136 \\
\hline Empowerment-Esteem & 30.3 & 5.26 & 29.3 & 4.57 & 0.880 & 0.351 \\
\hline Empowerment-Power & 19.5 & 3.58 & 19.8 & 3.62 & 0.133 & 0.716 \\
\hline Empowerment-Activism & 20.1 & 2.93 & 18.7 & 2.96 & 4.737 & $0.032^{*}$ \\
\hline Empowerment-Control & 12.6 & 1.60 & 11.4 & 2.10 & 7.211 & $0.009^{* *}$ \\
\hline Empowerment-Anger & 9.5 & 1.74 & 9.8 & 1.68 & 0.810 & 0.370 \\
\hline Control-Internal & 10.9 & 3.44 & 9.7 & 2.67 & 3.270 & 0.074 \\
\hline Control-Chance & 7.1 & 2.87 & 7.6 & 3.03 & 0.584 & 0.447 \\
\hline Control-Powerful others & 7.7 & 2.88 & 7.4 & 2.32 & 0.249 & 0.619 \\
\hline Self-esteem & 21.4 & 4.63 & 20.9 & 4.75 & 0.211 & 0.647 \\
\hline Self-efficacy & 61.2 & 12.03 & 59.3 & 9.31 & 0.753 & 0.388 \\
\hline Change situation coping & 10.2 & 2.23 & 10.4 & 2.25 & 0.140 & 0.709 \\
\hline Accommodation coping & 10.1 & 2.36 & 10.1 & 1.88 & 0.012 & 0.915 \\
\hline Symptom reduction coping & 9.0 & 2.15 & 8.9 & 2.18 & 0.017 & 0.897 \\
\hline Devaluation coping & 7.8 & 2.45 & 8.1 & 2.76 & 0.293 & 0.589 \\
\hline Avoidance coping & 7.2 & 2.68 & 7.3 & 2.72 & 0.081 & 0.776 \\
\hline Employment commitment & 64.6 & 8.08 & 61.8 & 10.33 & 1.815 & 0.181 \\
\hline Social support & 23.8 & 11.65 & 20.7 & 13.38 & 1.204 & 0.275 \\
\hline Satisfaction social support & 25.4 & 8.22 & 26.5 & 6.98 & 0.461 & 0.499 \\
\hline Psychological distress & 13.5 & 8.73 & 13.6 & 6.94 & 0.003 & 0.959 \\
\hline Perceived stress & 23.5 & 8.31 & 24.5 & 8.16 & 0.343 & 0.559 \\
\hline Depression & 16.6 & 11.07 & 17.2 & 11.31 & 0.056 & 0.813 \\
\hline
\end{tabular}

Notes. ${ }^{*} p<0.05$, two-tailed; ${ }^{* *} p<0.01$, two-tailed.

\section{Discussion}

We used a global measure of empowerment, the Making Decisions Scale (Rogers et al., 1997), together with several psychometric variables theoretically linked to empowerment, on a sample of 97 unemployed people in Luxembourg. The subjects had been jobless for 6 months and therefore were at risk of becoming long-term unemployed 6 months later. This sample may seem small compared to some established but poorly validated "rules of thumb" in psychometrics. However, hypothetical and real research examples have shown that sample sizes of at least 50 and not more than 100 are adequate for the evaluation and representation of psychological variables (Sapnas \& Zeller, 2002). 


\section{Reliability, Convergent and Divergent Validity}

We first studied convergent validity of the global empowerment scale and of the 5 subscales with the other measured psychometric dimensions. We found that the Power and the Anger scale were not psychometrically sound and that there were no intercorrelations between several subscales. But convergent and discriminant validity with several adaptive and non-adaptive dimensions could be established for the global and the Esteem, Power, Control and to a lesser degree for the Activism subscales. Most of our a priori theoretical links could be confirmed by bivariate correlation calculations between variables. But, correlations for the single Esteem subscale (9 items) were nearly as significant as for the global empowerment scale (28 items), throwing some doubt on the usefulness of the total scale. There were also several additional, unexpected correlations that were significant; these relations mostly fit with the theory, even if they are not all obvious. These first series of results are best explainable by an unjustified aggregation of several, loosely related constructs under the common heading of empowerment.

Multiple regressions and structural equation modelling showed that up to $42 \%$ of the variance of global empowerment measures could be explained by well-known and well-studied classical constructs: change coping, depression, and chance perceived control of unemployment, three dimensions different from the 5 dimensions that are supposed to be components of empowerment. In published studies, the highest variances that can be found are in general in the $50 \%$ to $60 \%$ range. So, $42 \%$ of the variance of global empowerment is a quite high figure and would probably be increased only marginally by adding more constructs in the multiple regressions.

This means that unemployed people who are more "empowered" are in fact more disposed to change situations they experience, are less depressed, and are less incline to believe that outcomes of their unemployment situation are a matter of chance. The relatively vague and imprecise concept of empowerment could be replaced by a far more accurate psychological description using three well-known and extensively studied psychometric constructs.

\section{Predictive Validity of Empowerment on Unemployment Duration}

In a next step, we studied predictive validity of the empowerment scales and of all the other psychometric scales with employment status 6 months later, i.e., at a moment where unemployed became long-term unemployed. We did this by comparing results on all the scales on the group of employed with the group of unemployed people. We found that 2 of the 5 subscales (Activism and Control) were linked to employment status 6 months later, and that the total empowerment scale did not. All the other psychometric scales did not permit differentiation between the two groups. This may mean that in profiling unemployed people to detect risk of long-term unemployment, two subscales of the whole tool give better results than the global empowerment scale. It is also true that these two scales provide better results in predictive validity for a real-life outcome, which is to find a job, than the more traditional concepts used in unemployment research, like self-esteem, self-efficacy, coping, social support, psychological distress, etc.

\section{Conclusions}

The overall results of our study throw some doubt on the pertinence of the global empowerment concept assessed by an aggregate measure and summing up a cocktail of somewhat divergent dimensions. As at least two of the subscales individually were linked to a real-life outcome, i.e., employment status 6 months later, and 
that intercorrelations between subscales is not established, it is proposed to use instead more specific and individualised constructs. This seems to be the direction taken with a more general population by researchers in the field like Zimmerman (1990). The latter measured empowerment with four distinct "psychometrically sound” (p. 77) scales: political efficacy, perceived competence, internal locus of control, and desire for control, but refused to create a global aggregate measure out of these scales. In an earlier study, Zimmerman and Rappaport (1988) used 11 different scales as "indices of empowerment” (p. 725) and showed their differential pertinence for community involvement. The important critical question in both cases however remains: Is the concept of empowerment still necessary?

\section{References}

Arneson, H., \& Ekberg, K. (2006). Measuring empowerment in working life: A review. Work, 26, 37-46.

Aujoulat, I., d'Hoore, W., \& Deccache, A. (2007). Patient empowerment in theory and practice: Polysemy or cacophony? Patient Education and Counseling, 66, 13-20. doi:10.1016/j.pec.2006.09.008

Bolton, B., \& Brookings, J. (1998). Development of a measure of intrapersonal empowerment. Rehabilitation Psychology, 43, 131-142. doi:10.1037/0090-5550.43.2.131

Castelein, S., van der Gaag, M., Bruggeman, R., van Busschbach, J. T., \& Wiersma, D. (2008). Measuring empowerment among people with psychotic disorders: A comparison of three instruments. Psychiatric Services, 59, $1338-1342$. doi:10.1176/appi.ps.59.11.1338

Chamberlin, J. (1997). A working definition of empowerment. Psychiatric Rehabilitation Journal, 20, 43-46.

Cohen, S., Kamarck, T., \& Mermelstein, R. (1983). A global measure of perceived stress. Journal of Health and Social Behavior, 24, 385-396. doi:10.2307/2136404

Corrigan, P. W. (2006). Impact of consumer-operated services on empowerment and recovery of people with psychiatric disabilities. Psychiatric Services, 57, 1493-1496. doi:10.1176/appi.ps.57.10.1493

Corrigan, P. W., Faber, D., Rashid, F., \& Leary, M. (1999). The construct validity of empowerment among consumers of mental health services. Schizophrenia Research, 38, 77-84. doi:10.1016/S0920-9964(98)00180-7

Edwards, J. R. (1992). A cybernetic theory of stress, coping, and well-being in organizations. Academy of Management Review, 17, 238-274.

Edwards, J. R., \& Baglioni, A. J. Jr. (1993). The measurement of coping with stress: Construct validity of the Ways of Coping Checklist and the Cybernetic Coping Scale. Work \& Stress, 7, 17-31. doi:10.1080/02678379308257047

Fresco, D. M., Coles, M. E., Heimberg, R. G., Liebowitz, M. R., Hami, S., Stein, M. B., \& Goetz, D. (2001). The Liebowitz Social Anxiety Scale: A comparison of the psychometric properties of self-report and clinician-administered formats. Psychological Medicine, 31, 1025-1035. doi:10.1017/S0033291701004056

Gibson, C. H. (1991). A concept analysis of empowerment. Journal of Advanced Nursing, 16, $354-361$. doi:10.1111/j.1365-2648.1991.tb01660.x

Goldberg, D. (1972). The detection of psychiatric illness by questionnaire. London: Oxford University Press.

Guppi, A., Edwards, J. A., Brough, P., Peters-Bean, K. M., Sale, C., \& Short, E. (2004). The psychometric properties of the short version of the Cybernetic Coping Scale: A multigroup confirmatory factor analysis across four samples. Journal of Occupational and Organizational Psychology, 77, 39-62. doi:10.1348/096317904322915900

Hansson, L., \& Bjorkman, T. (2005). Empowerment in people with a mental illness: Reliability and validity of the Swedish version of an empowerment scale. Scandinavian Journal of Caring Science, 19, 32-38. doi:10.1111/j.1471-6712.2004.00310.x

Hasluck, C. (2004). Targeting services in the individual customer strategy: The role of profiling. A review of research evidence. Warwick, UK: Institute for Employment Research, University of Warwick.

Kanfer, R., Wanberg, C. R., \& Kantrowitz, T. M. (2001). Job search and employment: A personality-motivational analysis and meta-analytic review. Journal of Applied Psychology, 86, 837-855. doi:10.1037/0021-9010.86.5.837

Kessler, R. C., Turner, J. B., \& House, J. S. (1989). Unemployment, reemployment, and emotional functioning in a community sample. American Sociological Review, 54, 648-657. doi:10.2307/2095885

Kirsh, B. (2000). Factors associated with employment for mental health consumers. Psychiatric Rehabilitation Journal, 24 , 13-21. doi:10.1037/h0095128 
Kosciulek, J. F., \& Merz, M. A. (2001). Structural analysis of the consumer-directed theory of empowerment. Rehabilitation Counseling Bulletin, 44, 209-216. doi:10.1177/003435520104400403

Latka, M. H., Metsch, L. R., Mizuno, Y., Tobin, K., Mackenzie, S., Arnsten, J. H., \& Gourevitch, M. N. (2006). Unprotected sex among HIV-positive injection drug-using women and their serodiscordant male partners: Role of personal and partnership influences. Journal of AIDS, 42, 222-228. doi:10.1097/01.qai.0000214813.50045.09

Levenson, H. (1973). Multidimensional locus of control in psychiatric patients. Journal of Consulting and Clinical Psychology, 41, 397-404. doi:10.1037/h0035357

Liebowitz, M. R. (1987). Social phobia. Modern Problems of Pharmacopsychiatry, 22, 141-173. doi:10.1159/000414022

Lucas, R. E., Clark, A. E., Georgellis, Y., \& Diener, E. (2004). Unemployment alters the set point for life satisfaction. Psychological Science, 15, 8-13. doi:10.1111/j.0963-7214.2004.01501002.x

McKee-Ryan, F. M., Song, Z., Wanberg, C. R., \& Kinicki, A. J. (2005). Psychological and physical well-being during unemployment: a meta-analytic study. Journal of Applied Psychology, 90, 53-76. doi:10.1037/0021-9010.90.1.53

Perkins, D. D. (1995). Speaking truth to power: Empowerment ideology as social intervention and policy. American Journal of Community Psychology, 23, 765-794. doi:10.1007/BF02506991

Provencher, H. L., Gregg, R., Mead, S., \& Mueser, K. T. (2002). The role of work in the recovery of persons with psychiatric disabilities. Psychiatric Rehabilitation Journal, 26, 132-144. doi:10.2975/26.2002.132.144

Radloff, L. S. (1977). The CES-D Scale: A self-report depression scale for research in the general population. Applied Psychological Measurement, 1, 385-401. doi:10.1177/014662167700100306

Rogers, E. S., Chamberlin, J., Ellison, M. L., \& Crean, T. (1997). A consumer-constructed scale to measure empowerment among users of mental health services. Psychiatric Services, 48, 1042-1047. doi:10.1176/ps.48.8.1042

Rogers, E. S., Ralph, R. O., \& Salzer, M. S. (2010). Validating the Empowerment Scale among with a multi-site sample of consumers of mental health services. Psychiatric Services, 61, 933-936. doi:10.1176/appi.ps.61.9.933

Rosenberg, M. (1965). Society and the adolescent self-image. Princeton, New Jersey: Princeton University Press.

Sapnas, K. G., \& Zeller, R. A. (2002). Minimizing sample size when using exploratory factor analysis for measurement. Journal of Nursing Measurement, 10, 135-154. doi:10.1891/jnum.10.2.135.52552

Sarason, I. G., Levine, H. M., Basham, R. B., \& Sarason, B. R. (1983). Assessing social support: The Social Support Questionnaire. Journal of Personality and Social Psychology, 44, 127-139. doi:10.1037/0022-3514.44.1.127

Sherer, M., Maddux, J., Mercandante, B., Prentice-Dunn, S., Jacobs, B., \& Rogers, R. (1982). The Self-Efficacy Scale: Construction and validation. Psychological Reports, 51, 663-671. doi:10.2466/pr0.1982.51.2.663

Spreitzer, G. (1995). Psychological empowerment in the workplace: Dimensions, measurement, and validation. Academy of Management Journal, 38, 1442-1465. doi:10.2307/256865

Taris, T. W. (2002). Unemployment and mental health: A longitudinal perspective. International Journal of Stress Management, 9 , 43-57. doi:10.1023/A:1013067101217

Townsend, E. (1998). Good intentions overruled: A critique of empowerment in the routine organization of mental health services. Toronto, Canada: University of Toronto Press.

Wallston, K. A., Wallston, B. S., \& DeVellis, R. (1978). Development of the Multidimensional Health Locus of Control (MDHL) Scales. Health Education Monographs, 6, 160-170. doi:10.1177/109019817800600107

Wowra, S. A., \& McCarter, R. (1999). Validation of the Empowerment Scale with an outpatient mental health population. Psychiatric Services, 50, 959-961. doi:10.1176/ps.50.7.959

Zimmerman, M. A. (1995). Psychological empowerment: Issues and illustrations. American Journal of Community Psychology, 23, 581-599. doi:10.1007/BF02506983

Zimmerman, M. A. (1990). Toward a theory of learned hopefulness: A structural model analysis of participation and empowerment. Journal of Research in Personality, 24, 71-86. doi:10.1016/0092-6566(90)90007-S

Zimmerman, M. A., \& Rappaport, J. (1988). Citizen participation, perceived control, and psychological empowerment. American Journal of Community Psychology, 16, 725-750. doi:10.1007/BF00930023 